Journal of Current and Advance Medical Research

July 2017, Vol. 4, No. 2, pp. 44-47

http://www.banglajol.info/index.php/JCAMR

ISSN (Print) 2313-447X

ISSN (Online) 2413-323X

DOI: http://dx.doi.org/10.3329/jcamr.v4i2.36354

ORIGINAL ARTICLE

OPEN ACCESS

\title{
Risk of Teenager Pregnancy in Adverse Neonatal Outcome: A Hospital Based Case-Control Study
}

\author{
Rumi Farhad Ara ${ }^{1}$, Jahangir Alam² \\ ${ }^{1}$ Associate Professor, Department of Gynaecology \& Obstetrics, Kushtia Medical College, Kushtia, Bangladesh; ${ }^{2}$ Associate \\ Professor, Department of Surgery, Shaheed Suhrawardy Medical College, Dhaka, Bangladesh
}

[Reviewed: 30 January 2017; Accepted on: 1 March 2017; Published on: 1 July 2017]

\section{Abstract}

Background: Teenage pregnancy is a risk of adverse neonatal outcome. Objective: The purpose of the present study was to estimate the risk of teenage pregnancy in the adverse neonatal outcomes. Methodology: This case-control study was conducted in the Department of Obstetrics and Gynecology at Dhaka Medical College \& Hospital, Dhaka, Bangladesh and Sir Salimullah Medical College \& Mitford Hospital, Dhaka, Bangladesh from April to July 1999 for a period of four (4) months. The teenage mothers with the age group of 11 to 19 years who were admitted in the study period was selected as case and pregnant women with the age group of more than 19 years were selected as control group. Perinatal mortality rate was calculated by foetal death after 28 weeks of gestation up to death within one week of delivery per 1000 live births. At birth, babies were examined for any congenital malformation. Gestational age of infants was assessed by Perkins' scoring system. Babies were assessed by Apgar score at 1 and 5 minutes. Result: A total number of 100 pregnant mothers were recruited for this study of which 50 pregnant mothers were in the case group and the rest 50 mothers were in the control group. Thirty-two babies of teenage mothers were asphyxiated at birth and $56.0 \%$ were healthy. At 1 minute, $52.0 \%$ babies of teen mothers have more than 7 Apgar score, whereas $86.0 \%$ babies born to non-teen mothers showed a Apgar score more than 7 which was also a significant difference. Among the cases, $54.0 \%$ babies have birth weight $>2.5 \mathrm{~kg}$. On the other hand, $72.0 \%$ of babies of non-teen mothers have birth weight $>2.5 \mathrm{~kg}$. Higher rate of perinatal morbidity in terms of birth asphyxia, prematurity, intrauterine growth retardation (IUGR), jaundice and septicaemia was found among the neonates of teen mothers than non-teen mothers. Conclusion: In conclusion birth asphyxia, prematurity, intrauterine growth retardation, jaundice and septicaemia are most commonly found among the neonates of teen mothers than non-teen mothers. [Journal of Current and Advance Medical Research 2017;4(2):44-47]

Keywords: Risk estimation; teenage pregnancy; adverse; neonatal outcomes

Correspondence: Dr. Rumi Farhad Ara, Associate Professor, Department of Gynaecology \& Obstetrics, Kushtia Medical College, Kushtia, Bangladesh; Email rumidr12@ gmail.com; Cell no.: +8801711480437

Cite this article as: Ara RF, Alam J. Risk of Teenager Pregnancy in Adverse Neonatal Outcome: A Hospital Based Case-Control Study. J Curr Adv Med Res 2017;4(2):44-47

Conflict of Interest: All the authors have declared that there was no conflict of interest.

Funding: This research project was not funded by any group or any institute on.

Contributions to authors: RFA has contributed in protocol preparation up to surgical procedures as well as the report writing; furthermore, RFA \& JA have written the manuscript and have revised the manuscript.

Copyright: (O2017 Ara et al. Published by Journal of Current and Advance Medical Research. This article is published under the Creative Commons CC BY-NC License (https://creativecommons.org/licenses/by-nc/4.0/). This license permits use, distribution and reproduction in any medium, provided the original work is properly cited, and is not used for commercial purposes. 


\section{Introduction}

Adolescent pregnancy is defined as gestation in women before having reached the full somatic development ${ }^{1}$. The percentage of childbearing adolescent women is regionally highly variable depending on cultural, religious, political, economic and other factors. Pregnancy in the very young is generally considered to be a high risk event because of the additional burden imposed by reproduction on a still growing body ${ }^{2}$. The perinatal mortality rate (PMR) is high at the extremes of the reproductive age which is 18 and 35 years $^{3}$. A woman's childhood legacy of short stature, low body weight and anaemia, early marriage, and childbearing before attainment of social and biological maturity are important causes of low birth weight (LBW) which in turn leads to increased perinatal deaths ${ }^{4}$.

Teenage pregnancy is often unplanned and results in a girl becoming a parent before becoming an adult. The foetuses of teenage mothers are at increased risk from different risk factors associated with maternal youth, primiparity and abnormal health behaviour ${ }^{5}$. The increased rates of preeclampsia and higher incidence of operative delivery among the teenagers affect adversely the perinatal outcome ${ }^{6}$. In this context this present study was undertaken to estimate the risk of teenage pregnancy in the adverse neonatal outcomes.

\section{Methodology}

This was a case-control study. This study was conducted in the Department of Obstetrics and Gynecology at Dhaka Medical College \& Hospital, Dhaka, Bangladesh and Sir Salimullah Medical College \& Mitford Hospital, Dhaka, Bangladesh from April to July 1999 for a period of four (4) months. The teenage mothers with the age group of 11 to 19 years who were admitted in the study period was selected as case and pregnant women with the age group of more than 19 years were selected as control group. Pregnancy status was confirmed by ultrasonography and other relevant test. After formulation of aims and objectives of the study, a data sheet and questionnaire form was made for recording all relevant parameters and these were then compared between control and cases. Careful history and thorough clinical examinations were performed with the aim of detecting any clinical symptoms and signs suggesting of or warning complication of pregnancy and delivery including perinatal complications. At entry into the study, a detailed history about past history, present history record of antenatal cheek-up and present complications were studied and a comparison of these variables was made between case and control group. On admission into the labour ward, a questionnaire was tilted-up. Age of the patient was calculated in years and was recorded accordingly.

Gestational age was recorded by the date of last menstrual period or by the month since the patient has amenorrhoea or by USG report at early weeks of gestation where available. Available standard care was provided to all. Perinatal mortality rate was calculated by foetal death after 28 weeks of gestation up to death within one week of delivery per 1000 live births.

At birth, babies were examined for any congenital malformation. Gestational age of infants was assessed by Perkins' scoring system. Babies were assessed by Apgar score at 1 and 5 minutes. The age distribution and birth weight of babies of two groups were recorded in grams and analyzed.

Results were analyzed by $\mathrm{Z}$ test (proportion test). Probability values $<0.05$ and $<0.001$ were considered significant and highly significant respectively. Statistical analysis was performed by the Statistical package for the Social Science (SPSS, Texas, USA) version 22.0. The qualitative variables were expressed as frequency and percentage.

\section{Result}

A total number of 100 pregnant mothers were recruited for this study of which 50 pregnant mothers with the age group of 11 to 19 years of age were in the case group and the rest 50 mothers were in the control group who were more than 19 years of age.

Table 1: Foetal Outcome in Teen and Older Patients

\begin{tabular}{|l|c|c|c|}
\hline Condition & $\begin{array}{c}\text { Case } \\
\text { Group }\end{array}$ & $\begin{array}{c}\text { Control } \\
\text { Group }\end{array}$ & $\begin{array}{c}\text { P } \\
\text { value }\end{array}$ \\
\hline Healthy & $28(56.0 \%)$ & $39(78.0 \%)$ & 0.05 \\
\hline Asphyxiated & $16(32.0 \%)$ & $10(20.0 \%)$ & 0.05 \\
\hline Stillborn & $5(10.0 \%)$ & $1(2.0 \%)$ & - \\
\hline $\begin{array}{l}\text { Congenital } \\
\text { malformation }\end{array}$ & $1(2.0 \%)$ & $0(0.0 \%)$ & - \\
\hline Total & $\mathbf{5 0}(\mathbf{1 0 0 . 0 \%})$ & $\mathbf{5 0}(\mathbf{1 0 0 . 0 \%})$ & \\
\hline
\end{tabular}

Thirty-two babies of teenage mothers were asphyxiated at birth and $56.0 \%$ were healthy. 
Congenital malformation was found in $1(2.0 \%)$ case in the case group. However there was no cases foun din the control group. Still born was found in $5(10.0 \%)$ cases and $1(2.0 \%)$ case in the case group and control respectively. In control group, $78.0 \%$ neonates were healthy (Table 1).

Table 2: Apgar score at 1 minute and 5 minutes

\begin{tabular}{|c|c|c|c|c|}
\hline $\begin{array}{l}\text { Apgar } \\
\text { Score }\end{array}$ & $\begin{array}{c}\text { Case } \\
(n=50)\end{array}$ & $\begin{array}{c}\text { Control } \\
(\mathrm{n}=50)\end{array}$ & $\mathbf{Z}$ & $\begin{array}{c}\mathbf{P} \\
\text { Value }\end{array}$ \\
\hline \multicolumn{5}{|c|}{ At 1 minute } \\
\hline 0 to 3 & $6(12.0 \%)$ & $1(2.0 \%)$ & 2.00 & 0.05 \\
\hline 4 to 6 & $18(36.0 \%)$ & $6(12.0 \%)$ & 2.93 & 0.01 \\
\hline$>7$ & $26(52.0 \%)$ & $43(86.0 \%)$ & 3.95 & 0.001 \\
\hline \multicolumn{5}{|c|}{ At 5 minutes } \\
\hline 0 to 3 & $5(10.0 \%)$ & $1(10.0 \%)$ & 3.40 & 0.001 \\
\hline 4 to 6 & $14(38.0 \%)$ & $4(8.0 \%)$ & & - \\
\hline$>7$ & $31(62.0 \%)$ & $45(90.0 \%)$ & 3.40 & 0.001 \\
\hline
\end{tabular}

Apgar score showed significant difference between the two groups. Twelve percent neonates of teenage mothers were severely asphyxiated (Apgar score 0 to 3), which was significantly higher than control group (4\%). At 1 minute, $52.0 \%$ babies of teen mothers have more than 7 Apgar score, whereas $86.0 \%$ babies born to non-teen mothers showed a Apgar score more than 7 which was also a significant difference (Table 2).

\section{Table 3: Distribution of Birth Weight}

\begin{tabular}{|c|c|c|c|}
\hline $\begin{array}{l}\text { Birth } \\
\text { Weight }\end{array}$ & Case & Control & $\begin{array}{l}\mathbf{P} \\
\text { Value }\end{array}$ \\
\hline$<2.5 \mathrm{~kg}$ & $23(46.0 \%)$ & $11(22.0 \%)$ & $<0.05$ \\
\hline$>2.5 \mathrm{~kg}$ & $27(54.0 \%)$ & $39(78.0 \%)$ & $<0.05$ \\
\hline Total & $50(100.0 \%)$ & $50(100.0 \%)$ & \\
\hline
\end{tabular}

Teen mothers delivered low birth weight babies (LBW) in significantly large number than older control group. Among the cases, $54.0 \%$ babies have birth weight $>2.5 \mathrm{~kg}$. On the other hand, $72.0 \%$ of babies of non-teen mothers have birth weight $>2.5$ $\mathrm{kg}$ (Table 3). There was significant difference in perinatal morbidity between the two groups. The result of the present study showed a higher rate of perinatal morbidity in terms of birth asphyxia, prematurity born before 37 completed weeks, intrauterine growth retardation (IUGR), jaundice and septicaemia among the neonates of teen mothers than non-teen mothers.

Significant difference was obvious in perinatal mortality between the two groups. It was higher among cases (18.0\%) than control (4.0\%) (Table 4).
Table 4: Perinatal Mortality among the study Population

\begin{tabular}{|c|c|c|c|}
\hline Mortality & $\begin{array}{c}\text { Case } \\
(n=50)\end{array}$ & $\begin{array}{l}\text { Control } \\
(n=50)\end{array}$ & $\begin{array}{l}\text { P } \\
\text { Value }\end{array}$ \\
\hline $\begin{array}{l}\text { Ante \& } \\
\text { Intrapartum } \\
\text { Foetal Death }\end{array}$ & $6(12.0 \%)$ & $1(2.0 \%)$ & - \\
\hline Neonatal & $3(6.0 \%)$ & $1(2.0 \%)$ & - \\
\hline Total & $9(18.0 \%)$ & $2(4.0 \%)$ & 0.05 \\
\hline
\end{tabular}

Prematurity was found more in the case group than control group which was $12(24.0 \%)$ cases and 2(4.0\%) cases respectively. Birth asphyxia was found more in the case group than control group which were $11(22.0 \%)$ and $3(6.0 \%)$ cases respectively (Table 5).

Table 5: Perinatal Morbidity among the study Population

\begin{tabular}{|c|c|c|c|}
\hline $\begin{array}{l}\text { Foetal } \\
\text { Condition }\end{array}$ & $\begin{array}{l}\text { Case } \\
(n=50)\end{array}$ & $\begin{array}{l}\text { Control } \\
(n=50)\end{array}$ & $\begin{array}{c}\mathbf{P} \\
\text { Value }\end{array}$ \\
\hline Prematurity & $12(24.0 \%)$ & $2(4.0 \%)$ & 0.01 \\
\hline $\begin{array}{l}\text { Birth } \\
\text { asphyxia }\end{array}$ & $11(22.0 \%)$ & $3(6.0 \%)$ & 0.05 \\
\hline IUGR & $12(24.0 \%)$ & $3(6.0 \%)$ & 0.05 \\
\hline Jaundice & $13(26.0 \%)$ & $3(6.0 \%)$ & 0.01 \\
\hline Septicaemia & $1(2.0 \%)$ & $0(0.0 \%)$ & - \\
\hline Birth injury & $0(0.0 \%)$ & $1(2.0 \%)$ & - \\
\hline Total & $50(100.0 \%)$ & $50(100.0 \%)$ & \\
\hline
\end{tabular}

\section{Discussion}

Teenage pregnancy is a medical and economic concern $^{2}$. It is a complex and frustrating problem that exacts a burden when the developing countries are struggling hard with limited resources to execute the obstetric services ${ }^{6}$. In Bangladesh the issues of perinatology and perinatal programme are mostly absent ${ }^{5}$. Unless the formative stage of human development is cured properly it cannot be expected human quality. Maternal nutrition is an important determinant of fetal growth, birth weight and infant mortality. The findings of anthropometric assessment by Bangladesh Integrated Nutrition Project in 44 sub district covering 14966 women of reproductive age has been found that $56.0 \%$ has a body mass index (BMI) $<18.5$ when the normal value taken as 25 to 28. The situation becomes alarming when a teenage girl becomes pregnant; besides malnutrition she is also biologically immature. Perinatal mortality and morbidity is a sign of negligence to women that should not be allowed to go on ${ }^{4}$. At every step of lifecycle of women they are prey of injustice which is affecting the next generation. Factors related to the teenage pregnancy are a multi-factorial issue, 
which is regulated by social, economic, biological, cultural situation and also highly related to women's position in the society ${ }^{6-11}$. Though a magic lamp is not in hand hut a sincere approach to the problem, preventative interventions and appropriate care during pregnancy, delivery and to neonates can do much in improving the situation ${ }^{7}$.

The present study was done on 100 primi gravida patients admitted in Dhaka Medical College Hospital and Sir Salimullah Medical College and Mitford Hospital, Dhaka. These are the important referral hospitals of the country. The present study found 24 percent IUGR. These figures agree with Pal et $\mathrm{al}^{3}$ which are $25.0 \%$ and $27.5 \%$ respectively. In this study, significant difference is observed in birth weight of baby between two groups which are $46.0 \%$ in teenage patients and $22.0 \%$ in older control groups $(\mathrm{p}<0.05)$. In study of Ali and Lulseged $^{4}$ adolescent pregnancy was found to be significantly associated with higher rates of premature baby and LBW infants $(\mathrm{p}<0.001)$ which is comparable to present study. DuPlessis et $\mathrm{al}^{7}$ in their study on adolescent pregnancy found that women of young maternal age are approximately 2.5 times more likely to have a LBW infant. This is comparable to present study. In series of Lee et $\mathrm{al}^{8}$ the younger adolescent mothers had the highest percentage of both infants with LBW (10.6\%) and preterm births $(7.1 \%)$.

Study of Sayers and Powers ${ }^{9}$ have shown teenage pregnancy is an important risk for intrauterine growth retardation. For growth retardation, 18.0\% could be attributed to a maternal age under 20 years which is comparable to present study findings of $24.0 \%$ IUGR in teenage pregnant patients. In this study, infants of teenage mothers have lower Apgar scores at 1 and 5 minutes $(48 \%$ and $38.0 \%$ respectively) which is significantly higher than control group (14.0\% and $10.0 \%)$. The study of Ali and Lulseged ${ }^{4}$ agree with this where newborns of adolescent mothers had lower Apgar scores $(<7)$ and 1 and 5 minutes $(\mathrm{P}<0.001)$.

Among teen, perinatal death is $18.0 \%$ comparable to the study of Gazi et $\mathrm{al}^{5}$. Bucci el $\mathrm{al}^{6}$ studied the outcome of teenage pregnancy in Mozambique and concluded that LBW rate is significantly $(\mathrm{P}<0.01)$ higher among women under 19 years than older ones. There are some limitations of this study. Great majority of childbirths take place at home with help of traditional birth attendants or family members and there is no civil registration. So, from this small percent of population who attend the hospital, exact situation of the whole country cannot be calculated. Hospital stay is only for a short period. Therefore exact number of perinatal mortality and morbidity is underestimated.

\section{Conclusion}

In conclusion a higher rate of birth asphyxia, prematurity, intrauterine growth retardation, jaundice and septicaemia are found among the neonates of teen mothers than non-teen mothers. Furthermore neonatal mortality is more common in teenage pregnant mother. It has been recommended that large scale study should be carried out to see the real picture of the country.

\section{References}

1. Sai TF. Adolescent sexuality and reproductive health. In: Mati JKG, Ladipo AO, Burleman RT, et al, Eds., Reproductive health in Africa, John Hopkins' Programme for International Education in Gynaecology and Obstetrics, Bangkok, 2006;16-30

2. Akhter HH, Rahman MH, Alnnctl S. Reproductive health issues and implementation strategies in Bangladesh. BIRPERHT, Dhaka, May 1996

3. Pal A, Gupta KB, Randhawa I. Adolescent pregnancy: a high risk group. Journal of the Indian Medical Association 1997;95(5):127-8

4. Ali M, Lulseged S. Factors influencing adolescent birth outcome. Ethiopian Medical Journal 1997;35(1):35-42

5. Gazi R, Goodburn L, Chowdhury AM. Risk factors for perinatal deaths in rural Bangladesh. Journal of Health \& Population in Developing Countries 1999;2(1):70

6. Bucci A, Mttnhiczt GM. Matchungo li Bugatlho, Uttini MC. Outcome of teenage pregnancy in Muputo. Int $\mathbf{J}$ Obstet Gynecol 1993; 40:19-23

7. DuPlessis HM, Bell R, Richards T. Adolescent pregnancy: understanding the impact of age and race on outcomes. Journal of Adolescent Health 1997;20(3):187-97

8. Lee MC, Suhng LA, Lu TH, Chou MC. Association of parental characteristics with adverse outcomes of adolescent pregnancy. Family Practice 1998;15(4):336-42

9. Sayers S, Powers J. Risk factors for aboriginal low birth weight, intrauterine growth retztrclzttion und preterm birth in the Darwin Health Region. Aust NZ J Public Health 1907; 21:524-30

10. Bangladeshi National Food and Nutrition Policy. 1997. MOHFW, Bangladesh

11. Rahman S, Nessa F, Ali R, Ara AH. Reproductive health of adolescents in Bangladesh. Intl Gynaecol Obstet 1989; 29329-35 